\title{
ALGUNAS REFLEXIONES SOBRE LA PERSPECTIVA DE GÉNERO Y EL PODER DE CASTIGAR DEL ESTADO*
}

\author{
Paz Lloria García**
}

Resumen: Este trabajo recoge algunas consideraciones en relación con los riesgos de identificar la creación e interpretación de normas penales desde la perspectiva de género con posiciones punitivistas o limitadoras de garantías penales (materiales o procesales), incompatibles con una concepción del feminismo progresista que huye de los sistemas utilitaristas extremos y autoritarios.

Palabras Clave: Interpretación normativa. Creación normativa. Perspectiva de género. Feminismo. Derecho penal.

Recibido: enero 2020. Aceptado: abril 2020

* Este trabajo se ha realizado en el marco del Proyecto de Investigación "La violencia sobre la mujer en el s. XXI: género, derecho y TIC", de la Generalitat Valenciana (Proyecto AICO 002/2017).

**Titular de Derecho Penal. ORCID ID: https://orcid.org/0000-0003-1515-6561 Departamento de Derecho Penal. Facultad de Derecho de la Universidad de Valencia. Avda. dels Tarongers, s/n, 46022, Valencia. Email: Lloria@uv.es 


\begin{abstract}
This paper gathers some considerations in relation to the risks of identifying the creation and interpretation of criminal legislation from a gender perspective with punitive or limiting positions of criminal guarantees (material or procedural), incompatible with a progressive feminism conception which flees from utilitarian and authoritarian systems.
\end{abstract}

Keywords: Normative interpretation. Normative creation. Gender mainstreaming. Feminism. Criminal Law.

\title{
1. Introducción
}

El abordaje del análisis de la perspectiva de género es una cuestión que nos ocupa en los últimos tiempos en muchas facetas. En el ámbito jurídico se presenta como una categoría analítica a tener en cuenta tanto en el momento de nacimiento de las normas como en el de su aplicación.

Para ello, es necesario aceptar como premisa que el derecho tiene una naturaleza fundamentalmente androcéntrica, pues fue creado por y para los hombres. Está idea de que el derecho adopta una base androcéntrica está extendida entre el feminismo jurídico. En este sentido FACIO pone de manifiesto como el feminismo debe llevar a cabo una Teoría crítica del derecho. De este modo, será posible clarificar cómo la base del derecho es fundamentalmente androcéntrica. Desde esta construcción no se puede aspirar a una realización de las normas que tengan en cuenta un verdadero significado de género, pues la dimensión patriarcal del mismo solo tolera y promueve la incorporación de la mujer a las filas de los "grandes juristas" cuando su aportación alimenta el sentido patriarcal de las normas. Por ello, para cambiar el enfoque jurídico hay que construir una Teoría crítica del derecho tomando en consideración las categorías que revelen relaciones asimétricas de poder, desde posiciones epistemoló- 
gicas feministas, tomando como referencia el sujeto, elemento imprescindible en esta materia ${ }^{1}$.

En esta línea, también se encuentra la obra de OLSEN donde, a partir de la concepción de un sistema dual en el que lo femenino ocupa una posición de subordinación frente a lo masculino se afirma que:

"Se identifica el derecho con los lados jerárquicamente superiores y "masculinos" de los dualismos. Aunque la "justicia" sea representada como una mujer, según la ideología dominante el derecho es masculino y no femenino. Se supone que el derecho es racional, objetivo, abstracto y universal, tal como los hombres se consideran a si mismos. Por el contrario, se supone que el derecho no es irracional, subjetivo o personalizado, tal como los hombres consideran que son las mujeres.

Las prácticas sociales, políticas e intelectuales que constituyen el derecho fueron, durante muchos años, llevadas a cabo casi exclusivamente por hombres. Dado que las mujeres fueron por largo tiempo excluidas de las prácticas jurídicas, no sorprende que los rasgos asociados con las mujeres no sean muy valorados en el derecho. Por otra parte -en una especie de círculo vicioso-, se considera que el derecho es racional y objetivo, entre otras cosas, porque es valorado y, a su vez, es tan valorado porque se lo considera racional y objetivo"2.

1 FACIO, A.: "Hacia otra teoría crítica del Derecho", en HERRERA, G.: Las fisuras del patriarcado. Reflexiones sobre Feminismo y Derecho. Ponencias en el Programa de Género de FLACSO organizadas por el seminario "Género y Derecho: reflexiones desde la teoría y la práctica”, Ecuador, 2000, págs. 15 a 44, passim, disponible en http://www.flacso.org.ec/docs/safisfacio.pdf).

2 OLSEN, F.: "El sexo del derecho", en KAIRYS, D. (ed.). The Politics of Law, Nueva York: Pantheon. Traducción de Mariela Santoro y Christian Courtis, págs. 3 y 4, disponible en http://www.derechoshumanos.unlp.edu. ar/assets/files/documentos/el-sexo-del-derecho.pdf

También resulta interesante por su relación con las distintas tesis feministas Bodelón, E.: "Derecho y justicia no androcéntricos", en Quaderns de psicología, núm. 2, 2010, págs. 184 y 185. 
Así, no queda otro remedio que intentar conjugar dicha formación normativa con una interpretación acorde a las necesidades propias del momento histórico que estamos viviendo de defensa de los derechos de la mujer, reconocidos como derechos humanos ${ }^{3}$ pero sin vulnerar los principios esenciales que limitan el poder punitivo del Estado y que no pueden ser obviados si queremos mantener una concepción del derecho penal y de la pena, propios de un Estado democrático de derecho que concibe el injusto como esencialmente neutro y la culpabilidad por el hecho, dejando al margen del castigo consideraciones morales que no pertenece al Estado reprobar, algo que, parece, en los últimos tiempos se está olvidando ${ }^{4}$.

En el ámbito penal, varias son las vertientes en las que esta perspectiva puede aplicarse y que pueden generar dudas con el planteamiento de inicio 5 :

3 Así, recientemente se ha pronunciado de manera contundente el llamado Convenio de Estambul (Convenio del Consejo de Europa sobre prevención y lucha contra la violencia contra la mujer y la violencia doméstica, hecho en Estambul el 11 de mayo de 2011, disponible en https://www.boe.es/diario_boe/txt.php?id=BOE-A-2014-5947).

4 Esto es, hay que reinterpretar el Derecho tomando en cuenta la necesidad de que las estructuras creadas por y para los hombres puedan realizarse desde una perspectiva de género, sin olvidar los límites que se establecen en un Estado democrático de derecho al poder de castigar, lo que permite una interpretación universal sin fisuras de discriminación por género. En palabras de FACIO, A.: "Hacia otra teoría...", cit., pág. 19.

"Para que una teoría logre el autoesclarecimiento de las luchas y deseos del movimiento feminista con respecto al Derecho, tendría que utilizar categorías y metodologías que revelen, en vez de ocultar, las relaciones de dominación masculina y subordinación femenina. Una de esas metodologías que tendría que utilizar sería la de la reconstrucción como método de análisis de los conceptos supuestamente neutros para demostrar su verdadera naturaleza androcéntrica, así como para visibilizar las relaciones de poder que oculta. Asimismo, tendría que recurrir a distintas formas de hacer crítica, como por ejemplo, testimonios o narrativas que permitan construir realidades sociales alternativas al tiempo que faciliten la protesta contra la aceptación acrítica de métodos y discursos que dejan por fuera gran parte de las distintas formas que toma la opresión a las mujeres".

5 LARRAURI PIJOAN realizó la distinción entre mujer víctima y mujer infractora a estos efectos en su trabajo "La mujer ante el Derecho penal", $R D P C$, n. 2, 1992, págs. 1 a 22. 
- la primera se dirige a observar el comportamiento de la mujer infractora, perspectiva que debe analizarse desde un punto de vista criminológico, -por qué y cómo delinquen las mujeres, lo que escapa de este trabajo ${ }^{6}$ - desde el punto de vista penal, teniendo en cuenta cómo la situación por razón de género de estas mujeres puede influir en supuestos de atenuación o incluso de exención de la pena, y también en su ejecución ${ }^{7}$ y tratamiento penitenciario ${ }^{8}$, llevándonos al escenario de la violencia institucional9.

- la segunda, tiene que ver con la mujer víctima de violencia. Es necesario analizar el tratamiento social e institucional que se proporciona a las mujeres víctimas, para evitar, de una parte, su re-victimización y la interpretación de sus comportamientos en clave de culpabilidad y de otra, para evitar la hiperprotección que lleva al paternalismo.

— por último, cómo se puede justificar (si resulta necesario) un tratamiento punitivo diferente para los varones cuando atentan contra las mujeres por el hecho de ser mujeres. Aquí hay

6 Se puede ver la obra de MAQUEDA ABREU, M.L.: Razones y sin razones para una criminología feminista, Dikynson, 2014, passim.

7 Vid., ACALE SÁNCHEZ, M.: "El género como factor condicionante de la victimización y de la criminalidad femenina", en Papers, 102/2, 2017, págs. 6 y ss.

8 Que tampoco corresponde tratar aquí. Vid., CRUZ MÁRQUEZ, B.: "Configuración legal y desarrollo normativo de la práctica penitenciaria frente a la delincuencia de género", en Juanatey Dorado, C. y Sánchez Moraleda, N. (Dir.): Derechos del condenado y necesidad de pena, Aranzadi, 2019, págs. 346 a 352. Pueden consultarse también las Reglas de Bangok, para el tratamiento de las internas elaboradas por Naciones Unidas y disponibles con comentarios en https://www.unodc.org/documents/justice-and-prisonreform/Bangkok Rules ESP 24032015.pdf. Todo ello sin olvidar las torturas específicas que sufren las mujeres en tiempos de guerra, que tienen claramente contenidos sexuales con la finalidad de causar una mayor degradación de la integridad moral y la dignidad.

9 Del que también escapa este trabajo. Vid., por todos, BODELÓN, E.: "La violencia contra las mujeres y derecho no androcéntrico: perdidas en la traducción jurídica del feminismo", en Laurenzo Copello, P., Maqueda Abreu, M.L. y Rubio Castro, A.M. (Coords.): Género, violencia y derecho, Tirant lo Blanch, 2008. 
que desglosar dos realidades: los sistemas de protección de las mujeres frente a los ataques de sus parejas y los sistemas de protección frente al ataque que procede de otros hombres ${ }^{10}$.

Los primeros aspectos no plantean excesivas dudas desde el punto de vista de las garantías. La víctima de violencia de género debe ser tratada con una especial sensibilidad y formación y hay que huir de las distintas situaciones que la llevan a la revictimización, del mismo modo que se realiza con otro tipo de víctimas que se encuentran en situación de vulnerabilidad, lo que no significa que se destruyan las garantías del derecho de defensa del imputado (investigado) ni la presunción de inocencia.

Tampoco han de surgir muchas cuestiones en relación con la idea de que resulta necesario valorar las diferentes circunstancias que rodean a las personas a la hora de cometer delitos. Y que, en el caso de las mujeres, debe incluir un análisis de su situación por el hecho de ser mujeres. Tal y como se puede explicar, debería tomarse en cuenta lo importante que resulta, o bien realizar una correcta interpretación de las circunstancias que afectan a la imputabilidad o a la exigibilidad cuando se trate de mujeres que se encuentran en situación de desigualdad o de explotación, o bien, establecer supuestos específicos de atenuación o exención de las penas en atención a las circunstancias que han llevado a las mujeres a cometer ciertos delitos.

Sin embargo, en el ámbito puramente punitivo, a la hora de castigar los hechos que cometen los varones sobre las mujeres por razones de discriminación de género, es donde más problemas nos podemos encontrar. Las diferencias de trato, cuando se refieren a una elevación de las penas, siempre plantean dudas sobre la ineludible aplicación objetiva de la norma que la dota

10 Vid., LLORIA GARCÍA, P.: "La violencia sobre la mujer en el S. XXI: Sistemas de protección e influencia de las tecnologías de la información y la comunicación en su diseño", en Lloria García, P. (Dir.) y Cruz Ángeles, J.: (Coord.): La violencia sobre la mujer en el S. XXI: Género, Derecho y TIC, Aranzadi, 2019, págs. 26 a 32. 
de seguridad jurídica (proyección inexcusable del principio de legalidad) y el resto de garantías. En esta situación, tres son, al menos, los principios que se pueden ver afectados con una interpretación automática y acrítica de la perspectiva de género como categoría analítica: el principio de igualdad, el principio de culpabilidad y el de presunción de inocencia.

Con estas premisas, mi propósito es doble:

- por un lado, creo necesario concretar qué es "la perspectiva de género"; de qué hablamos cuando nos referimos a este planteamiento desde el punto de vista normativo y si puede servir o no como categoría analítica en el derecho penal.

- por otro lado, se trata de analizar cómo la jurisprudencia aborda estas cuestiones y, sobre todo, comprobar si resulta posible o no realizar una interpretación de las normas sancionadoras que sea respetuosa con dichas garantías y que no sirva de excusa para fomentar derechos penales autoritarios que conviertan a los hombres en enemigos convenientes, dando así paso a una fundamentación feminista del populismo punitivo lo que sería contradictorio en sí mismo.

\section{La perspectiva de género como categoría analítica}

La perspectiva de género se presenta como una categoría analítica tradicionalmente empleada en la sociología y la antropología que hoy debe trasladarse al ámbito de la interpretación del Derecho, aunque no de una manera absoluta, automática y acrítica como he adelantado ${ }^{11}$.

Ciertamente, es necesario recordar que la creación del Derecho como conjunto normativo dispuesto para resolver los conflictos de convivencia está pensado por y para el hombre, en

11 Sobre esta cuestión se pronuncia también QUINTERO OLIVARES, G.: "La tutela penal: entre la dualidad de bienes jurídicos o la perspectiva de género en la violencia contra la mujer", Estudios penales y criminológicos, vol. XXIX, 2009, págs. 426 a 429. 
una sociedad regida por el principio de que es el varón el que ostenta el poder $y$, por lo tanto, el que tiene capacidad para involucrarse en dichos conflictos y resolverlos. El patriarcado hace mella en el orden objetivo y en el subjetivo del derecho.

Desde un punto de vista objetivo, el orden normativo es un mecanismo de socialización patriarcal. El Derecho crea diferencias de género en su regulación ordinaria: atribuye roles, sexualiza y prima a un rol sobre otro. Y, aunque se presente de una manera aparentemente neutra, como una creación aplicable a sujetos que se encuentran en posición de igualdad, lo cierto es que existe una importante desigualdad estructural, que debe ser equilibrada desde el momento de creación de la norma, o en el momento de su aplicación.

Recuérdese la presencia de los delitos honoris causa hasta hace poco (en términos de evolución histórica del derecho) como el infanticidio o el aborto honoris causa, el castigo del adulterio en las mujeres que solo tenia un correlativo en el amancebamiento, y las graves afrentas contra el honor de una mujer, si su honestidad se veía puesta en entredicho ${ }^{12}$.

El análisis histórico del derecho penal puede ser una importante vía clarificadora para entender la idea que se expone ${ }^{13}$.

En este sentido creo que se puede traer a colación la STS de 21 de mayo de 1951, en el que se trata un supuesto en el que una vez que la mujer ha accedido a tener un encuentro sexual con promesa de matrimonio, no quiere seguir con las relaciones, y el hombre amenaza con contarlo. Esa situación de afectación del honor de la mujer, que en el año de referencia de la Sentencia tenía que ver con la consideración de la mujer como un ser de

12 Cfr., LARRAURI PIJOAN, E.: Género y Derecho penal, disponible en http://www.cienciaspenales.net/files/2016/09/5generoyderechopenal11.elenalarrauri.pdf

13 Interesantes son las aportaciones de QUINTERO OLIVARES en este sentido. En especial, la minuciosa explicación sobre el uxoricidio. (Vid., QUINTERO OLIVARES, G.: "La tutela penal: entre la dualidad..., cit., págs. 429 a 436). 
"sexualidad adormecida" 14 , se sigue produciendo en la actualidad, ahora no contándolo, sino enseñándolo.

Si se analiza el caso del art. 197.7 que recoge el delito de difusión inconsentida de imágenes intimas, en el marco del sistema de protección de las conductas que afectan a las mujeres en nuestro Código penal, con una especial referencia al sexting ajeno como pornovenganza, se detecta un sutil abandono de la perspectiva de género y se incluyen en el tipo agravado la equiparación de sujetos -hombre/mujer- como si la conducta fuera de igual gravedad, cuando es un caso claro en el que si se difunden las imágenes de una mujer practicando sexo las consecuencias para su honor son más lesivas que para el hombre, teniendo en cuenta la concepción social que sigue imperando de la mujer como sujeto pasivo sexual ${ }^{15}$.

Todo esto tiene que ver con que normativamente se sigue ignorando la realidad social ${ }^{16}$ y con la consideración de la mujer con roles diferentes a los hombres, lo que el legislador debe valorar a la hora de establecer la norma.

La visión androcéntrica denunciada históricamente se perpetúa, también, en la idea de que los conflictos que no se resuelven de manera privada, o en los que existe un interés público, son los que deben regularse normativamente, quedando

14 Según la Sentencia del Tribunal Supremo de 31 de mayo de 1974.

$15 C f r$. LLORIA GARCÍA, P.: "La regulación penal en materia de violencia familiar y de género tras la reforma de 2015. Especial referencia al ámbito tecnológico", en $R G D P$, núm. 31, 2019, págs. 30 y 31, siguiendo a ALONSO DE ESCAMILLA, A.: "La reforma de los delitos contra la intimidad" en Morales Prats, F., Tamarit Sumalla, J.M. y García Albero, R. (Coord.): Represión penal y Estado de Derecho. Homenaje al Profesor Gonzalo Quintero Olivares, Aranzadi, 2019, págs. 767 y 768.

16 No se pueden olvidar los casos de Tiziana Cantone y de Verónica Rubio, dos mujeres que acabaron suicidándose como consecuencia de la difusión de videos en los que aparecían en actitudes sexuales explícitas. Se puede ver sobre este último algunas consideraciones que he realizado a propósito del mismo en "El control tecnológico como violencia de género" disponible en http://agendapublica.elpais.com/el-control-tecnologico-como-violencia-degenero/ 
en la esfera de lo privado los conflictos a resolver por aquel que tiene potestad para hacerlo: el varón. Así, por ejemplo, hay que recordar que queda fuera del ámbito de intervención del derecho $\mathrm{y}$, en concreto, del Derecho penal, todo aquello que el Estado considera que puede encontrar solución de una manera más liviana, incluso dentro del propio ámbito familiar, si entiende que no existe un interés público en la persecución, lo que lógicamente tiene que ver con el principio de intervención mínima, pero también con otros factores.

Recuérdese, por ejemplo, la previsión del art. 268 del CP que contiene una cláusula personal de exclusión de la pena por los delitos patrimoniales no violentos cometidos entre sí por determinados familiares. El fundamento de esta exención radica en que la familia posee mecanismos de resolución del conflicto suficientes como para que no haya injerencias estatales, siempre que no hablemos de una situación de violencia o abuso de la vulnerabilidad de la víctima, lo que ha sido criticado por la doctrina.

En primer lugar, porque hay que abandonar la idea de que el pater familias puede resolver todo con su autoritas.

En segundo lugar, porque nos podemos encontrar con situaciones límite, en las que no se podrá perseguir el hecho y este constituirá, precisamente, una situación de violencia de género en forma de violencia económica. Piénsese en situaciones en las que, dentro del matrimonio, o constante la relación de pareja, se sustrae el dinero del control de la mujer o los bienes de la pareja, o incluso los privativos de la misma, como una medida de dominación, en la que resulta muy difícil demostrar la existencia de violencia o intimidación. No habría posibilidad de intervenir penalmente, salvo que se llegara a la conclusión de que se está ejerciendo alguna forma de violencia física o psíquica sobre la mujer.

Ello nos lleva a recordar que la creación de la norma, y por lo tanto su aplicación, corresponde tradicionalmente a los hombres, retomando la idea ya expuesta de la naturaleza androcéntrica del derecho. 
Por otro lado, es común advertir que las normas han de ser interpretadas según el momento histórico en el que han de ser aplicadas, y si una disciplina debe beber de dicha regla, esa es el Derecho penal.

El Derecho penal se presenta como ese espejo de la sociedad que regula las peores acciones que un ser humano puede cometer contra sus congéneres y, por ello, establece sanciones que, en consecuencia, deber ser adecuadas al daño producido a bienes jurídicos esenciales ${ }^{17}$.

Todo ello, sin perder de vista que en un derecho penal democrático el propio Estado se ve limitado por los principios que disciplinan el poder de castigar. Límites de los que no escapan los operadores jurídicos y especialmente los jueces, cuando han de establecer sus sentencias.

$\mathrm{Y}$, aquí, es donde resulta necesario recordar la importancia de la creación y la aplicación del derecho de la manera más neutra posible, sin olvidar, claro está, que una sentencia acaba siendo redactada por una persona, que resulta influenciada por su propia formación, entorno social, educativo, etc. ${ }^{18}$. Los jueces tienen una experiencia de la vida y una concepción de las personas y de las cosas, por lo que, como claramente afirma RUIZ-RICO 19 "participan de los mismos prejuicios que existen en la sociedad en que se encuentran y para la cual administran justicia”.

Es decir, lo que se denomina la perspectiva subjetiva. La labor del operador jurídico no es mecánica, es creativa cuando ha de aplicar la norma (que es general) a unos hechos concretos

17 Esto es, atendiendo al principio de proporcionalidad, al de intervención mínima y última ratio y al de ofensividad.

18 Un minucioso análisis sobre la fundamentación de las resoluciones judiciales en materia de libertad sexual y la influencia de los estereotipos en las mismas se puede ver en CUGAT MAURI, M.: "La ambivalencia de la protección...", cit., passim.

19 Ruiz Rico, J.J.: El sexo de sus Señorias, $4^{\mathrm{a}}$ ed., mayo-2011, Madrid, Comares, pág. 2. 
(que son particulares) y su subjetividad está lógicamente condicionada por el patriarcado (y por el capitalismo) ${ }^{20}$.

Si vivimos en una sociedad patriarcal, no cabe la menor duda de que muchas aplicaciones normativas lo serán ${ }^{21}$.

Los prejuicios que adornan a algunas resoluciones judiciales nos hacen entrar en el mundo de los estereotipos de género contra los que hay que luchar, en una sociedad que se pretenda más justa y que busque la igualdad como directriz imprescindible a seguir. Si desde el punto de vista objetivo la norma ha de ser general y lo más neutra posible ${ }^{22}$, en el ámbito subjetivo el operador jurídico, sin vulnerar garantías, ha de atender a las circunstancias concretas del caso, y en el tema que ocupa este trabajo, a las circunstancias que afectan a la mujer por el hecho de ser mujer.

Lo que ocurre es sencillo de explicar y difícil de cambiar, sobre todo teniendo siempre los límites al poder de castigar como elementos ineludibles de la aplicación normativa.

La perspectiva de género, encuentra su origen en el gender mainstreaming ${ }^{23}$, y ha sido empleada tanto en la Plataforma

20 Es cierto que existen otras influencias, desde luego. Importantísimas son las que provienen de los medios de comunicación que llevan a exacerbar el populismo punitivo. En este sentido se puede ver un trabajo anterior, LLORIA GARCÍA, P.: "La expansión del Derecho penal en su aplicación judicial: la violencia de género como ejemplo paradigmático", en García Rivas, N. y Riquert, M.A.(Dirs.): Garantías penales en Argentina, España y sus sistemas de inserción regional, Ediar, Buenos Aires, 2011, págs. 79 y ss. Estas influencias mediáticas han sido estudiadas con profusión por GARCÍA ARÁN, M. y BOTELLA CORRAL, J. (DIRS.): Malas noticias. Medios de comunicación, política criminal y garantías penales en España, Tirant lo Blanch, 2009, passim.

21 Con independencia de que la impartan hombres o mujeres, pues el patriarcado a todos/todas nos afecta.

22 Lo que me lleva a optar por un sistema de protección penal que escape del simbolismo y busque el equilibrio mediante la creación de una circunstancia genérica que pueda prever la desigualdad y corregirla y no a través de un sistema de derecho penal sexuado.

23 La expresión es confusa y ha generado muchas críticas por la dificultad de su traslación al castellano. En esencia, implica la necesidad de que todas las 
de la acción de Beijing ${ }^{24}$, como en otros cuerpos normativos, como el Convenio de Estambul. Este último contiene indicaciones para los Estados en el sentido de que deben incluir dichas perspectivas en sus normativizaciones con el fin de alcanzar la igualdad material en la regulación de derechos. Se indica, igualmente, cómo dichos derechos, se recogen en sus textos legislativos.

Pero no es suficiente. También hay que tomar en consideración la perspectiva de género a la hora de interpretar y aplicar las normas que ya han sido creadas en el entorno androcéntrico, con la finalidad de dar cumplimiento al mandato de economía legislativa y al de interpretar las normas según el momento histórico en el que han de ser aplicadas.

Un análisis de la jurisprudencia, sobre todo en materia de libertad sexual nos muestra cuál es la pulsión de los tribunales sobre cuestiones delicadas, como los lugares en los que se practica el sexo, o las tipologías de hombres y mujeres y los roles que les son asignados socialmente según el momento en que han de ser aplicadas.

acciones públicas o privadas, aunque especialmente las políticas públicas, sean entendidas de un modo transversal tomando en cuenta las específicas necesidades de la igualdad de género. Como afirma GARCÍA PRINCE, se trata de que el gender mainstreaming en "(...) las políticas públicas representa una completa y real inserción de la perspectiva de igualdad de género (...)en todas sus fases, (diseño, formulación, adopción y ejecución), y en todas ellas, habrá que admitir que todas las políticas públicas, cualquiera que sea el sector de que se trate, son políticas de igualdad y no reservar esta denominación a unas cuantas políticas públicas. Esto es lo que en futuro plantea el propósito de igualdad a través del mainstreaming de genero" (GARCÍA PRINCE, E.: Políticas de Igualdad, Equidad y Gender Mainstreaming. ¿De qué estamos hablando?: Marco Conceptual. Edición revisada y actualizada, disponible en http://www.americalatinagenera.org/es/documentos/doc_732_Politicasdeigualdad23junio08.pdf).

24 Que se refirió al concepto como "la necesidad de tener en cuenta el impacto de género antes de que las decisiones sean adoptadas" (Vid., POYATOS, G.: "Prólogo", en Gisbert, S.: Balanza de género, Lo que no existe, 2018, p. 9, nota 3 ). 
La perspectiva de género a lo que nos obliga es a interpretar la norma olvidando dichos prejuicios. No se trata, como algunos pretenden, de establecer normas que supongan necesariamente una discriminación positiva que favorezca a las mujeres a base de vulnerar el principio de igualdad (lo cual sería muy discutible, por otra parte) ni de crear un principio de presunción de culpabilidad o de olvidar el derecho de defensa ${ }^{25}$.

La perspectiva de género solo implica que las normas deben ser aplicadas atendiendo a la situación de discriminación que sufren las mujeres por su propia condición de tal manera que se garantice una aplicación igualitaria de la norma (no uniformadora) y que deje de lado las consideraciones subjetivas prevalentes en la sociedad sobre los papeles que las mujeres deben cumplir y que se relacionan con los tradicionales mitos de la mujer madre, del amor romántico y de la pasividad sexual femenina, así como de la idea del control por parte del Derecho a las propias mujeres a las que no se permite autodeterminarse libremente ni, por lo tanto, tomar decisiones que tengan que ver con

25 Este discurso está calando hondo en la sociedad española. Desde la Sentencia del denominado caso de la Manada en instancia, se está generando un movimiento social que va más allá de la petición de justicia, sustituyéndolo por el de venganza, en una sutil manipulación de las masas que viven el dolor de las víctimas como propio, produciéndose una transferencia que implica que se olviden los principios garantistas y se convierta al agresor en enemigo carente de derechos, dentro de la lógica expansiva del derecho penal autoritario. Las advertencias de SILVA SÁNCHEZ sobre el curioso cambio que se está produciendo, donde los grupos más progresistas, los feministas, adoptan roles de autoritarismo propio de las dictaduras lo empezamos a vivir, tristemente. (SILVA SÁNCHEZ, J.M.: La expansión del Derecho penal: aspectos de la política criminal en las sociedades postindustriales, Edisofer, 2011, epígrafe 2.8).

La recentísima sentencia del denominado "Caso de la Arandina" con una pena absolutamente desproporcionada y una valoración de los hechos más que dudosa con el principio de presunción de inocencia, puede dar al traste con las legítimas aspiraciones de crear una justicia con perspectiva de género correcta. Precisamente por ello no se puede dejar de recordar que el feminismo siempre ha luchado en contra de las posiciones autoritarias y se han defendido las garantías propias de un pensamiento progresista. 
su propio cuerpo o su propia libertad de pensamiento, religiosa e incluso económica ${ }^{26}$.

El abandono de los estereotipos de género será un primer paso para poder analizar y aplicar las normas con esa perspectiva de género, que no es más que entender las normas tomando en consideración las desigualdades que sufren las mujeres y obviando los estereotipos de género.

Pues bien, desde esta premisa, se puede decir que la perspectiva de género es entonces, como afirma POYATOS ${ }^{27}$, una técnica de análisis holístico, contextualizado, que obliga a cumplir con el principio de que las normas han de ser interpretadas según el momento histórico en que han de ser aplicadas. Y este momento histórico exige que en cumplimiento, además, de mandatos normativos como el contenido en el art. 49.2 del Convenio de Estambul ${ }^{28}$, las normas se orienten desde la perspectiva de género.

Por lo tanto, existe obligación de desprenderse de los estereotipos e introducir como elemento de la interpretación la perspectiva de género.

\section{La aplicación de la perspectiva de género en la interpreta- ción jurídico-penal}

Los operadores jurídicos han de tomar como punto de partida la idea de que han de abandonar los estereotipos de gé-

26 Toda esta idea esta presente en la obra de FACIO, A.: Cuando el género suena, cambios trae: (Una metodología para el análisis de género del fenómeno legal), Ilanud, 1992, passim.

27 POYATOS, G.: "Prólogo", en Gisbert S.: Balanza ..., cit., p. 9.

28 Dispone:

"Las Partes adoptarán las medidas legislativas o de otro tipo necesarias, de conformidad con los principios fundamentales de los derechos humanos y teniendo en cuenta la perspectiva de género en este tipo de violencia, para garantizar una investigación y un procedimiento efectivos por los delitos previstos en el presente Convenio". 
nero. Esta premisa, repetida varias veces, me parece ineludible. Pero, también me parece irrenunciable la idea de que esta obligación no nos puede llevar a justificar incrementos de pena o a la renuncia de principios penales (materiales y procesales) que conduzcan a utilizar la categoría analítica como excusa para adoptar tesis autoritarias o funcionalistas que deriven en la consideración del hombre como enemigo ${ }^{29} \mathrm{o}$ en la creación de derechos penales de excepción ${ }^{30}$.

Volviendo a las vertientes a las que aludía en la introducción, quiero intentar explicar cómo se podría aplicar la perspectiva de género sin hacer el juego a posiciones penales incompatibles con un Estado democrático y de derecho.

La perspectiva de género ha de ser tomada en consideración como un elemento más del análisis, y no puede suponer una aplicación automática y acrítica del principio de discriminación positiva, en lo que hace al Derecho penal.

Con este punto de partida, resulta necesario analizar los diferentes aspectos anunciados.

\subsection{El caso de la mujer infractora}

No hay ningún problema en aplicar dicha perspectiva en el caso de la mujer infractora (algo poco explorado por nuestra doctrina y jurisprudencia).

29 Se toma la idea que JAKOBS ha defendido, como es sabido, en relación con sujetos que se consideran peligrosos y a los que se castiga por los riesgos que pueden llegar a causar, en un sistema penal de varias velocidades con una relajación evidente de las garantías, hasta el punto de hacerlas desaparecer. (GÜNTHER,J./ CANCIO MELIÁ, M.: Derecho penal del enemigo, Civitas, 2006, passim). Un análisis de este posicionamiento y sus implicaciones en relación con la violencia de género se puede ver en OREJÓN SÁNCHEZ DE LAS HERAS, N.: La circunstancia agravante genérica de discriminación por razones de género, Iustel, 2019, págs. 103 a 138.

30 La crítica no es nueva. Autoras de referencia en esta materia se han pronunciado hace tiempo sobre estos riesgos. Vid., por todas, MAQUEDA ABREU, M.L.: "La violencia de género. Entre el concepto jurídico y la realidad social", $R E C P C$, 2005, pág. 2. 
No cabe duda que la mujer víctima de violencia puede reaccionar de manera que pueda ser calificada de delictiva frente a los ataques de su agresor, o bien, puede cometer delitos bajo la presión del agresor. La cuestión es si dichas acciones merecen algún tipo de atenuación y de qué clase.

En este sentido, se puede traer a colación la SAP de Madrid, 806/2018, de 17 de diciembre. Los hechos son más o menos los siguientes: A y B, matrimonio, en presencia de la hija discuten. Él le da un empujón, un puñetazo y le causa lesiones. La acorrala contra la pared, ella cree que existe riesgo para su vida "como consecuencia de evidencias de maltrato sufrido a lo largo de su vida con una pareja anterior, y re-experimentando dichas situaciones traumáticas, con ánimo de defenderse y acabar con la vida de él, con visión túnel, coge un cuchillo y se lo clava".

La condena es por una tentativa de homicidio con atenuante de legítima defensa incompleta y miedo insuperable.

Recurrida la resolución, el TSJ acaba condenando con una eximente de trastorno mental transitorio, y no por legítima defensa con falta de proporcionalidad del medio o por error. Esta condena puede implicar no actuar con perspectiva de género: la elección de la atenuante supone que, en lugar de aplicar la pena se aplica una medida de seguridad, lo que lleva de nuevo a considerar a la mujer como una incapaz que no sabe manejar sus emociones ${ }^{31}$.

La mayoría de las sentencias analizadas en que se producen hechos asimilables aplican el trastorno mental transitorio $\mathrm{u}$ otras circunstancias que toman como base la inimputabilidad de la mujer, con esa idea de incapacidad que, a primera vista, puede pasar por algo justificado pero que lleva a pensar en la afectación subjetiva por parte del juzgador y el olvido de la pers-

31 Algo similar denuncié cuando en el Proyecto de Ley del Aborto de Gallardón se eximía de responsabilidad penal a la mujer que abortaba, por lo que suponía de desconsideración hacia su capacidad en la toma de decisión y la consecuencia de tratarla como una incapaz. 
pectiva de género, pues quizá, las causas de justificación incompletas pudieran ser más adecuadas para resolver el conflicto. Sin embargo, se opta por las causas de inculpabilidad muchas veces de una manera inconsciente, atendiendo a prejuicios de género ${ }^{32}$.

La única resolución que, hasta ahora, he encontrado que alcance una respuesta como la propuesta (legítima defensa incompleta) es la Sentencia del Tribunal Supremo 22/2019, de 8 de enero. En ella se ventila un asunto en el que el varón pega a su pareja, le pone un cuchillo en el cuello, la amenaza de muerte y de agresión sexual. Deja el cuchillo cerca, ella lo coge y se lo clava provocándole una lesión leve. Él es condenado por un maltrato puntual y ella por unas lesiones con instrumento peligroso con eximente incompleta de legitima defensa ${ }^{33}$.

Otros casos que se pueden traer a colación son aquellos en los que la mujer comete delitos coaccionada por el hombre que la somete a maltrato. Son ejemplificativos los supuestos en los que las mujeres son obligadas a actuar como "mulas" de narcotráfico o cualquier otro delito, por sus parejas, bajo amenaza de mal constitutivo de delito para ellas o sus hijos ${ }^{34}$.

Para estos casos, se reclama la posibilidad de establecer alguna clausula similar a la exclusión de la pena prevista en el art. 177 bis $^{35}$ para las victimas de trata que se ven obligadas a cometer delitos.

32 Vid., LARRAURI PIJOAN, E.: "La mujer...”, cit., págs. 2 a 4.

33 Obviamente la situación es similar a la anterior. Ella teme por su vida/integridad, ha vivido episodios anteriores de violencia, y, sin embargo, no se aplica la idea de la disminución de la imputabilidad.

34 Cfr., ACALE SÁNCHEZ, M.: "El género como factor condicionante...", cit., pág. 5 .

35 En este precepto se dispone:

“(...) 11. Sin perjuicio de la aplicación de las reglas generales de este Código, la víctima de trata de seres humanos quedará exenta de pena por las infracciones penales que haya cometido en la situación de explotación sufrida, siempre que su participación en ellas haya sido consecuencia directa de la situación de violencia, intimidación, engaño o abuso a que haya sido sometida y que exista una adecuada proporcionalidad entre dicha situación y el hecho criminal realizado". 
No creo que haya ningún problema en incluir estas consideraciones a la hora de valorar la situación de las mujeres infractoras. No se vulnera ninguna garantía, sino que, por el contrario, se trata de adecuar la realidad de la situación que influye en su comportamiento y que desde luego está impregnada de sesgos de género. El hecho de convertirse en instrumentos de la acción de otro bajo coacción o amenaza debe ser tomado en consideración necesariamente, cuando la circunstancia concurra.

\subsection{El caso de la mujer víctima}

Este sería otro aspecto que considero que resulta imprescindible analizar en materia de perspectiva de género en el derecho penal.

La perspectiva de género ha de ser adoptada en este caso para evitar la revictimización y la culpabilización por el hecho sufrido.

Estoy pensando, sobre todo, en delitos donde los ataques estadísticamente generan que hablemos de bienes jurídicos de eminente titularidad femenina: fundamentalmente los delitos sexuales.

Ilustrar este epígrafe con algunos casos, puede dar una idea de cómo se ha ido evolucionando (o no), en esta materia ${ }^{36}$.

Son tristemente famosas algunas sentencias históricas donde la víctima acaba siendo culpabilizada por el ataque sufrido. La conocida "Sentencia de la Minifalda" (SAP de Lleida de 17 de febrero de 1989), confirmada posteriormente por el Tribunal Supremo ${ }^{37}$, en la que se dice que, si bien el acusado aprove-

36 CUGAT MAURI realiza un estudio de la evolución en materia tutela y conformación de los bienes jurídicos comprometidos en las actuaciones sexuales y la diferente valoración de los sujetos pasivos en atención a consideraciones morales, muy clarificador. Vid., Cugat Mauri, M.: "La ambivalencia de la protección de la libertad sexual. Jurisprudencia del Tribunal Supremo sobre el delito de violación", en Jueces para la Democracia, núm. 20, 1993,págs. 73 y ss.

37 Se puede ver la noticia en https://elpais.com/diario/1990/05/24/sociedad/643500002 850215.html 
chó su condición de patrono y jefe para realizarle tocamientos por encima de la ropa, ella con su vestido, quizá inocentemente, provocó la reacción en el hombre.

Aunque se podría pensar que esto son cosas del pasado ${ }^{38}$, lo cierto es que, muy recientemente han sido también noticia las preguntas de un fiscal a una víctima sobre la ropa que vestía en el momento de la situación del abuso denunciado ${ }^{39}$, o el caso también conocido por la prensa de unas menores que acudieron a denunciar un atentado sexual y no solo no fueron creídas por las agentes de policía que les tomaron la denuncia, sino que les reprocharon su actitud ${ }^{40}$.

En este escenario resulta necesario traer a colación la Sentencia del conocido como caso de "La Manada"41, aunque solo sea en su voto particular ${ }^{42}$. El pronunciamiento del magistrado disidente es una muestra de la necesidad de formación en género que requieren algunos operadores jurídicos ${ }^{43}$, para po-

38 LARRAURI PIJOAN pone de manifiesto algunos de los estereotipos que siguen estando vigentes: la mujer es la que provoca; las mujer dice no cuando quiere decir si; si se relajan, las mujeres disfrutan; las mujeres decentes (que están en su casa o con su marido) no son violadas, hay que protegerse de las denuncias falsas (mujeres despechadas, mentirosas, vengativas). Vid., LARRAURI PIJOAN, E.: "La mujer...", cit., págs.. 13 y 14.

39 https://www.publico.es/sociedad/agresion-sexual-fiscal-denunciante-violacion-pantalon-corto.html

40 https://www.publico.es/actualidad/trato-vejatorio-menor-denuncia-mossastrataron-denunciar-violacion-puedes-perrear-debes-defenderte.html

41 SAP de Navarra, 38/2018, de 20 de marzo.

42 No quiero entrar en el cuerpo de la Sentencia donde, desde mi punto de vista, se realizó una interpretación acorde a los principios garantistas del Derecho penal. Vid., entre otros, AAVV.: Las huellas de "La Manada", Monográfico de la Revista El Cronista del Estado Social y Democrático de Derecho, IUSTEL, 2018, núm. 77; también, OREJÓN SÁNCHEZ DE LAS HERAS, N.: "Derecho penal y cultura de la violación con ocasión del caso de "La Manada"”, en Lloria García, P. (Dir.). y Cruz Ángeles, J. (Coord.): La violencia sobre la mujer en el siglo XXI: género, derecho y TIC, págs. 113-136.

43 La formación en género no es una actualización de conocimientos jurídicos, sino una formación transversal que ayude a realizar una interpretación más objetiva y acorde al momento histórico de reconocimiento pleno de los derechos de las mujeres frente a la discriminación por motivos de género. 
derse desprender de estereotipos absolutamente interiorizados y que no pueden ser trasladados a la hora de llevar a cabo la interpretación normativa.

Una exégesis con perspectiva de género no hubiera autorizado dicho voto particular (por su forma, no por el fondo, aunque este viene condicionado, indudablemente, por dichos prejuicios). De hecho, la STS 2200/2019, de 4 de julio que casó la de la Audiencia, atiende, precisamente, a la situación en la que queda la mujer cuando es introducida en aquel lugar angosto para justificar la existencia de intimidación ambiental y poder castigar por un delito de violación a la pena de quince años de prisión ${ }^{44}$.

En esta vertiente, por tanto, es importante recordar dos aspectos: por un lado, el tratamiento que hay que dar a la víctima durante las exploraciones en fase de investigación y también en el juicio oral ${ }^{45}$, que han de llevarse a cabo con una especial sensibilidad y por otra, la credibilidad de la víctima y no culpabilizarla, sin vulnerar el principio de presunción de inocencia ${ }^{46}$.

Es el caso también de Tiziana Cantone, la joven italiana que practicó sexting, fue acosada, denunció y, una vez que

44 Similar argumentación para aplicar la intimidación ambiental se empleó en el caso de la denominada "Manada de Villalba", resuelto en la SAP de Madrid 2/2019, de 1 de febrero.

45 Hay quién plantea, incluso, cambiar la denominación del acto de investigación y/o de prueba, y que no se trate la declaración de la víctima como una simple testifical (JERICÓ OLER, L.: "Perspectiva de género, violencia sexual y derecho penal", en Monge Fernández, A. (Dir.): Mujer y derecho penal. ¿Necesidad de una reforma desde una perspectiva de género?, Bosch, 2019, pág. 319).

46 Sin olvidar otras consideraciones que se siguen teniendo en cuenta en otros delitos como los de lesiones. Recuérdese también el asunto Carvalho Pinto de Sousa, resuelto por el TDH en Sentencia de 25 de julio de 2017, donde el tribunal nacional había entendido que se podía rebajar la indemnización por las lesiones sufridas por una actuación médica imprudente en la medida en que el sexo para una mujer de 50 años había perdido importancia. Sobre este asunto se puede ver DABOVE, M.I. Y ARRUBIA, E.: “¿Demasiado vieja para el sexo?", en Derecho y Ciencias Sociales; núm. 19, disponible en http://sedici.unlp.edu.ar/handle/10915/70779 
se reconoció su derecho a que los videos fueran retirados se le condenó al pago de 20.000 euros en costas, dado que se había desprendido voluntariamente de su intimidad sin haber tomado en consideración las consecuencias que se derivarían de su actuación (en el ejercicio de su libertad sexual), lo que la llevó, finalmente, al suicidio ${ }^{47}$.

La falta de cuidado de la víctima, a la que se culpa de lo que le ocurre sigue estando muy presente ${ }^{48}$. Incluso en las formaciones de prevención en escuelas se advierte a las menores de que no deben practicar sexting, pues corren el riesgo de que luego sus imágenes sean utilizadas en su contra, lo que supone rebasar la idea de autoprotección para llevarla a la de autopuesta en peligro, con todas las cuestiones dogmáticas que ello plantea y que, desde luego, he de rechazar ${ }^{49}$.

47 https://verne.elpais.com/verne/2016/09/15/articulo/1473924999_823409. $\mathrm{html}$

48 Sería adecuado establecer protocolos de actuación en este sentido tal y como prescribe el Estatuto de la Víctima.

49 Como es sabido, la autopuesta en peligro actúa como criterio delimitador de la responsabilidad penal, cuando se atribuye a la víctima la falta de cuidado exigible para que el Derecho penal la tutele. En los casos analizados jurisprudencialmente de autopuesta en peligro se excluye la responsabilidad del autor cuando la víctima pudo elegir entre someterse al riesgo que se deriva en lesión o no. Por ejemplo, en la STS 2518/2017 de 21 de junio de 2017 se dice:

"La creación de un peligro jurídicamente desaprobado está ausente cuando se trate de riesgos permitidos, que excluyen la tipicidad de la conducta que los crea, y próximos a estos los casos de disminución del riesgo, en los que el autor obra causalmente respecto de un resultado realmente ocurrido, pero evitando a la vez la producción de un resultado más perjudicial. Son de mencionar igualmente otros supuestos de ruptura de la imputación objetiva entre los que se pueden incluir los abarcados por el principio de confianza, conforme al cual no se imputarán objetivamente los resultados producidos por quien ha obrado confiando en que otros se mantendrán dentro de los límites del peligro permitido, así como las exclusiones motivadas por lo que doctrinalmente se denomina la prohibición de regreso, referidas a condiciones previas a las realmente causales, puestas por quien no es garante de la evitación de un resultado.

El segundo requisito exige que el riesgo (no permitido) creado por la acción sea el que se realiza en el resultado. Es en este segundo condicionante de la 
El mensaje sigue siendo entonces, equivocado.

La atención y empatía con la víctima no trae problemas desde el punto de vista de las garantías del investigado, ni supone necesariamente una vulneración del derecho de defensa. La cuestión, entonces, se puede plantear, en relación con la credibilidad de la víctima cuando su testimonio es el que vertebra todo el procedimiento por no haber otros medios de prueba.

Dado que en la mayoría de casos de atentados contra la libertad sexual no suele haber testigos más allá de los autores y la víctima, es esencial atender a su testimonio, y en estos casos la inmediación es fundamental. Como también lo es evitar la revictimización, y tratar de fundamentar la prueba atendiendo a su situación, para poder verificar la veracidad de sus declaraciones teniendo en cuenta, por un lado, el estado de trauma en el que la mujer se encuentra, pero sin llegar a paternalismos absurdos ni a posiciones que vulneren el principio de presunción de inocencia $\mathrm{y}$ el de in dubio pro reo.

$\mathrm{Y}$ aquí hay que tomar en consideración no solo la problemática de la credibilidad de la víctima que puede incurrir en contradicciones o que puede llegar a no querer declarar haciendo uso de la dispensa que le concede el art. 416 de la LeCrim $^{50}$, sino

imputación objetiva en el que se plantea la presencia de riesgos concurrentes para la producción del resultado, cuestión en la que habrá que estar al riesgo que decididamente lo realiza, como aquellos otros casos en los que no podrá sostenerse la realización del riesgo en el resultado cuando la víctima se expone a un peligro que proviene directamente de su propia acción, en cuyo caso el resultado producido se imputará según el principio de la " autopuesta en peligro "o "principio de la propia responsabilidad". Se trata de establecer los casos en los que la realización del resultado es concreción de la peligrosa conducta de la propia víctima que ha tenido una intervención decisiva".

Sobre esta discutidísima cuestión en Derecho penal se pueden ver, entre otros, GIMBERNAT ORDEIG, E.: "Imputación objetiva y conducta de la víctima", disponible en https://www.boe.es/publicaciones/anuarios_derecho/abrir_pdf.php?id=ANU-P-2005-30073300806

50 Recientemente, con un estudio sobre la evolución jurisprudencial en esta materia, se puede ver BELTRÁN MONTOLIU, A.: "Víctima de violencia de género y la dispensa del art. 416 LeCrim: evolución jurisprudencial", en Revista de Derecho penal y Criminología, $3^{a}$ época, núm. 19 (enero de 
también el de la credibilidad de la víctima que está empoderada, que aparentemente no se encuentra lo afligida que debía estar según los estereotipos de género ${ }^{51}$.

Esto se deriva de la confusión que existe también en torno al concepto de víctima, cuando se olvida que es un concepto normativo y no sociológico y se incurre en su vulgarización ${ }^{52}$.

En todo caso, recientemente el Tribunal Supremo se ha pronunciado sobre esta cuestión. En la STS 678/2019, de 6 de marzo, se ventila un caso en el que se discute si el esposo ha llevado a cabo malos tratos habituales alegando que no existe voluntad de someter a la esposa y que el hecho de consumir alcohol habitualmente debería llevar a calificar los hechos como lesiones comunes y no género específicas ${ }^{53}$. Por su parte, la Au-

2018), págs. 13 a 46. Este aspecto merecería de un mayor tratamiento. El hecho de que la víctima se niegue a declarar ha llevado a algunos grupos a reclamar la desaparición de la norma. La jurisprudencia ha intentado una interpretación restrictiva, de tal manera que conduzca a la obligación de la denunciante a declarar cuando ella ha decidido no hacerlo (sea por las razones que sea). A mi modo de ver, esto supone también una quiebra de la perspectiva de género, pues se sitúa a la mujer en una situación en la que "debe ser protegida a toda costa" desconociendo los propios mecanismos de la mujer para sobre llevar la situación o su propia libertad para decidir, en una tutela excesiva que conduce a otro modo de violencia que tiene que ver con concepciones paternalistas que no toman en consideración la capacidad en la toma de decisiones. En similar sentido se puede ver VILLACAMPA ESTIARTE, C.: Política criminal española en materia de violencia de género. Valoración crítica, Tirant lo Blanch, 2018, págs. 108 a 111.

51 De nuevo hay que traer a colación el caso de "La Manada", en el que determinadas pruebas sobre cómo la víctima se comportaba en su vida ordinaria tras la agresión fueron aportadas para desmentir su testimonio. Desde mi punto de vista, dichas pruebas eran necesarias para la determinación de la responsabilidad civil, pero no para valorar la culpabilidad o inocencia de los hoy condenados. Vid., BODELÓN, E.: "Violencia Institucional y violencia de género", en Análes de la Cátedra Francisco Suarez, 48, 2014, pág. 143.

52 Vid., un resumen de las distintas concepciones en PÉREZ RIVAS, N.: Los derechos de la víctima en el sistema penal español, Tirant lo Blanch, 2017, págs. 1 a 38 .

53 La defensa se apoya en la idea de la no aplicación automática de los tipos género específicos, sino en la necesidad de demostrar que existe una voluntad de sometimiento que es lo que caracteriza las actuaciones machistas, en 
diencia entendió que no podía condenar por abuso sexual, puesto que no existía ninguna prueba que corroborase la versión de la víctima, por lo que debía absolver.

Ante esta tesitura el Tribunal Supremo analiza cuáles son los requisitos que deben concurrir para dotar de veracidad a la declaración de la víctima de tal modo que sea suficiente para enervar el principio de presunción de inocencia. Para ello, en primer lugar, expone cuáles son los requisitos que, con carácter general, se exigen para fundamentar que el testimonio de la víctima es válido según el proceso valorativo-subjetivo de los jueces, que disfrutan, además, de la inmediación:

"1.- Seguridad en la declaración ante el Tribunal por el interrogatorio del Ministerio Fiscal, letrado/a de la acusación particular y de la defensa.

2.- Concreción en el relato de los hechos ocurridos objeto de la causa.

3.- Claridad expositiva ante el Tribunal.

4.- "Lenguaje gestual" de convicción (...).

5.- Seriedad expositiva que aleja la creencia del Tribunal de un relato figurado, con fabulaciones, o poco creible.

6.- Expresividad descriptiva en el relato de los hechos ocurridos

7.- Ausencia de contradicciones y concordancia del "iter" relatado de los hechos.

8.- Ausencia de lagunas en el relato de exposición que pueda llevar a dudas de su credibilidad.

9.- La declaración no debe ser fragmentada.

10.- Debe desprenderse un relato integro de los hechos y no fraccionado acerca de lo que le interese declarar y ocultar lo que le beneficie acerca de lo ocurrido.

11.- Debe contar tanto lo que a ella y su posición beneficia como lo que le perjudica".

una interpretación sistemática de los tipos de derecho penal sexuado y el art. 1 de la LO 1/2004. 
Ahora bien, en el caso de las víctimas de violencia de género establece que, dada su situación, hay que tomar en consideración el temor de las mismas

“(...) a revivir lo sucedido al contarlo de nuevo al Tribunal, $y$ tras haberlo hecho en dependencias policiales y en sede sumarial, lo que junto con los factores que citamos a continuación pueden ser tenidos en cuenta a la hora de llevar a cabo el proceso de valoración de esta declaración, como son los siguientes:

1.- Dificultades que puede expresar la víctima ante el Tribunal por estar en un escenario que le recuerda los hechos de que ha sido víctima y que puede llevarle a signos o expresiones de temor ante lo sucedido que trasluce en su declaración.

2.- Temor evidente al acusado por la comisión del hecho dependiendo de la gravedad de lo ocurrido.

3.- Temor a la familia del acusado ante posibles represalias, aunque estas no se hayan producido u objetivado, pero que quedan en el obvio y asumible temor de las víctimas.

4.- Deseo de terminar cuanto antes la declaración.

5.- Deseo al olvido de los hechos.

6.- Posibles presiones de su entorno o externas sobre su declaración".

Ciertamente esta tesis viene a destruir el antiguo principio "testis unus, testis nullus", vigente en los sistemas de prueba legal o tasada, lo que puede resultar razonable tal y como afirma la STS 88/2015, de 17 de febrero ${ }^{54}$. Pero, no se puede olvidar que el testimonio único puede plantear serios problemas si la libre valoración de la prueba no viene condicionada por una motivación suficiente como para enervar el principio de presunción de inocencia, por lo que, en estos casos, procede la absolución ${ }^{55}$.

54 También atienden a la perspectiva de género en relación con el momento en el que la víctima presenta la denuncia las SSTS 247/2018, de 24 de mayo y la $184 / 2019$, de 2 de abril.

55 Un desarrollo de la idea de que no resultan aceptables los testimonios únicos sin corroboración para establecer una condena, y mucho menos cuando existen dudas razonables, se puede consultar en RAMÍREZ ORTIZ, J.L.: "El testimonio único de la víctima en el proceso penal desde la perspectiva 
Para evitar que el testimonio pierda su virtualidad, por tanto, el juzgador ha de atender a los criterios establecidos y ha de despojarse de los prejuicios de género. Pero debe motivar suficientemente aquello que le lleva a creer a la víctima, para evitar vulnerar derechos esenciales ${ }^{56}$.

Algo así ha ocurrido, a mi entender, en el caso conocido como "La Arandina", del que se ha ocupado la SAP de Burgos $379 / 2019^{57}$, y que posteriormente el TSJ de Castilla y León ha corregido en el sentido indicado ${ }^{58}$.

de género", en Quaestio Facti. Revista internacional sobre razonamiento probatorio, Vol. 1, 2019, págs. 1 a 46, disponible en https://revistes.udg.edu/ quaestio-facti/article/view/22288/26046

56 No puedo compartir el criterio de aquellas autoras que entienden que hay que partir de la premisa de que la relación sexual denunciada siempre ha sido inconsentida, pues supone una grave alteración de la carga de la prueba incompatible con los límites a los que estoy haciendo referencia a lo largo del texto. (Cfr., JERICÓ OJER, L.: "Perspectiva...", cit., págs. 323 y 324).

57 Los hechos relatan que una menor de 15 años, toma contacto con un jugador de un equipo de futbol de su pueblo, joven pero mayor de edad, con el que quiere entablar una relación. Después de tener conversaciones con él a través de redes sociales y por teléfono, bromea con él y dos amigos sobre la posibilidad de tener sexo grupal. Finalmente, quedan un día en casa de los jóvenes, y después de grabar un video musical en el que participan todos, se apagan las luces y ellos se desnudan, la desnudan a ella y les practica felaciones y masturbaciones. Cuando la chica va al cuarto de baño después de estos hechos, mantiene relaciones sexuales completas con uno de ellos en una habitación, con consentimiento, según el Tribunal. Se absuelve de esta última acción, pero se condena por una agresión sexual a cada uno de ellos por cada una de las felaciones, al entender que la joven de 15 años no tiene capacidad para consentir. Además, condena en concurso real como cooperador necesario a cada uno por las dos felaciones de los otros. La participación consiste en generar con su presencia lo que se conoce como "intimidación ambiental", lo que lleva a la aplicación de una pena de 38 años de prisión a cada uno, con el limite de cumplimiento de 20 . Sin embargo, se absuelve de la relación sexual con penetración vaginal producida inmediatamente después, pues entiende que el consentimiento de la menor en ese caso sí fue válido, al estar próxima en edad con el chico con el que mantuvo el coito (ella 15 y el 19), según lo que dispone el art. 183 quater del CP español. Toda la resolución se fundamenta en las declaraciones de la víctima, quién denuncia después de contarles a sus padres los hechos negando que ella consintiera, aunque en la causa constan conversaciones de ella con sus amigas participán- 
La aplicación de la perspectiva de género resulta clara, en la medida en que se atiende a que la idea de que la mujer por el hecho de acudir a un lugar privado (el domicilio de los chicos) no está demostrando su consentimiento para mantener la relación sexual grupal, a pesar de su comportamiento previo o sus manifestaciones ${ }^{59}$.

Sin embargo, en la resolución de Burgos se incurre en el temor que he manifestado anteriormente: la presión social sobre estas cuestiones, desde mi punto de vista ha llevado a dictar una sentencia que resulta muy peligrosa para las garantías, y en la que, de alguna manera, se ha instrumentalizado la legitima petición feminista de que la interpretación normativa se realice con perspectiva de género al punto de justificar una aplicación de la norma con vulneración de garantías penales (materiales y procesales básicas).

En primer lugar, la desproporción de la pena es evidente. Castigar unos hechos como los narrados con 38 años de prisión aplicando un concurso de normas, en un caso donde existe una unidad natural de acción (o las diferentes unidades típicas que se convierten en una unidad jurídica) que hubiera debido llevar a la aplicación de la figura del delito continuado, prevista en el art. 74 del CP, que castiga con la pena de la infracción más grave en su mitad superior pudiendo llegar a la mitad inferior de la pena superior en grado, lo que hubiera llevado a una pena de diez a doce años en el caso de considerarse abuso, o de trece años y seis meses a quince años si se contempla que la acción es constitutiva de agresión sexual, debe ser discutida.

doles lo que ha ocurrido con agrado e incluso amenazando con denunciar y "contar mentiras" si los chicos difunden lo que ha pasado entre ellos.

58 La Sentencia del TSJ de Castilla y León, 14/2020 de 18 de marzo se ha dictado durante el periodo de evaluación de este trabajo por lo que me voy a limitar a mencionar, brevemente, como en la misma, sin perder la perspectiva de género, se ha dictado una condena acorde al principio de presunción de inocencia y respetando, esencialmente, el derecho de defensa.

59 Interpretación similar realizó la Sentencia de la Audiencia Provincial de Navarra respecto del caso denominado "La Manada" SAP Navarra 38/2018, de 20 de marzo. 
En segundo lugar, tampoco resulta clara la aplicación de la situación de intimidación ambiental, que es la que fundamenta, según el Tribunal, tanto la apreciación del delito de agresión, en lugar del de abuso como el castigo como autores y cooperadores en concurso real.

Según la jurisprudencia aportada por el propio tribunal (Sentencia 609/2013, de 10 de julio), para apreciar la intimidación:

“(...) lo relevante es el contenido de la acción intimidatoria llevada a cabo por el sujeto activo más que la reacción de la victima frente a aquella. El miedo es una condición subjetiva que no puede transformar en intimidatoria una acción que en si misma no tiene ese alcance objetivamente.

Es preciso en este sentido, que, expuesta la intención del autor, la victima haga patente su negativa de tal modo que sea percibida por aquel. Que exista una situación intimidante que pueda considerarse suficiente para doblegar su voluntad, tanto desde un punto de vista objetivo, que atiende a las características de la conducta y a las circunstancias que la acompañan, como subjetivo, referido a las circunstancias personales de la víctima" 60 .

Sin negar el sentimiento de la víctima, una chica de 15 años que quiere demostrar madurez sexual y estar liberada, según se dice en la propia sentencia, sí considero que no atender a este criterio para contemplar, al menos la duda sobre la efectiva concurrencia del elemento intimidatorio, puede vulnerar el principio in dubio pro reo ${ }^{61}$. Siendo que las pruebas indiciarias circundantes a las manifestaciones de la propia víctima (contando a sus amistades que había estado con los tres y que no podían

60 Fundamento de derecho octavo.

61 No se hace mención a este principio en la Sentencia del TSJ de Castilla y León (14/2020), aunque sí se advierte que no puede existir intimidación porque el comportamiento de la víctima anterior y posterior al acto grupal resulta absolutamente incoherente con la interpretación de la intimidación ambiental y niega la falta de credibilidad subjetiva del relato de la víctima (fundamento de derecho octavo). 
contar nada pues entonces ella mentiría sobre los hechos y estaban avisados de las consecuencias), la propia manifestación de la perito psicóloga del juzgado diciendo que no tenía la madurez que quería aparentar, etc., considero que el principio de presunción de inocencia no queda totalmente desvirtuado en este caso.

Ciertamente no disponemos de la inmediación del Tribunal, y desde luego no es mí intención sustituirlo, pero sí es cierto que parece dudoso que en una situación como la descrita (están bailando y grabando videos en una casa, ella charla animadamente y les ha dicho previamente que quiere mantener sexo con los tres) objetivamente se pueda dar el requisito de la intimidación ambiental (sí, subjetivamente, pero esto no es suficiente) ${ }^{62}$.

Es decir, se puede creer que la víctima en aquel momento por su grado de madurez o por cualquier otra razón, no supo manejar la situación, por lo que, subjetivamente, ella pudo sentir que no quería hacer aquello que previamente había dicho que sí quería. Y esto, en su caso, y con muchas dudas, podría conducir a un abuso ${ }^{63}$, pero no a una agresión, porque objetivamente no basta con la declaración de la víctima que es contradictoria y que no se ve reforzada por pruebas periféricas, a aplicar la intimidación, pues objetivamente resulta difícil demostrar que existiera alguna actuación o creación de clima amenazante o intimidatorio.

Por lo demás, y aun en el caso de que se considerara que existe dicha intimidación ambiental por las declaraciones de la

62 La Sentencia del TSJ de Castilla y León (14/2020) realiza una alteración en los hechos probados aceptando la alegación de los recurrentes en atención a la falta de racionalidad de la valoración de la prueba y la falta de credibilidad de la declaración de la víctima (fundamentos de derecho sexto,séptimo y octavo).

63 Y nunca con prevalimiento, pues éste también exige de una actuación objetiva que difícilmente se deriva de lo reflejado en la sentencia. Sobre la cuestión relativa a la intimidación ambiental y el abuso con prevalimiento con perspectiva de género se puede ver JERICÓ OLER, L.: "Perspectiva de género...", cit., 304 a 326. Así lo ha entendido la Sentencia dictada por el órgano superior (fundamento de derecho noveno). 
víctima que, según la inmediación del tribunal y a pesar de la prueba indiciaria en contrario, son persistentes y coherentes, aplicar la teoría de la cooperación necesaria nos llevaría a un doble bis in ídem.

Por un lado, se produce la vulneración de la prohibición de doble incriminación porque el tribunal aplica el tipo agravado del art. 1832 y 3 (agresión sexual -intimidación ambientalcon penetración), con la agravante específica de actuar en grupo (183 4 b, cuando el hecho se produzca por la actuación conjunta de dos o más personas).

Por otro lado, si esta actuación conjunta es la que permite calificar el hecho como agresión, porque la presencia de más de dos es lo que genera el miedo y por lo tanto la intimidación, no puede volverse a utilizar para aplicar la agravación, que de suyo incrementa al injusto por la indefensión de la víctima. El fundamento es el mismo y siendo así, parece que la calificación vulnera el principio ne bis in ídem. Aun admitiendo entonces dicha concurrencia, o el hecho se califica como abuso agravado, o como agresión sin agravar.

Pero además, se aplica esta circunstancia (la presencia de varios autores) para fundamentar la cooperación necesaria, pues se entiende que es cooperador necesario,

"(...) no solo el que contribuye o coadyuva al acceso carnal ajeno, aportando su esfuerzo físico para doblegar la voluntad opuesta de la víctima, sino también aquel o aquellos que respondiendo a un plan conjunto ejecutan con otros una acción en cuyo desarrollo se realiza una violación o violaciones, aunque no se sujetase a la víctima porque la presencia de varios individuos concertados para llevar a cabo el ataque contra la libertad sexual conlleva en sí mismo un fuerte componente intimidatorio mucho más frente a una única joven y en lugar solitario.

En definitiva, este concepto de cooperación necesaria se extiende también a los supuestos en que, aun existiendo un plan preordenado se produce la violación en presencia de otros in- 
dividuos sin previo acuerdo, pero con conciencia de la acción que se realiza".

La vulneración de estos principios no debe llevar a olvidar la cuestionable consideración de la culpabilidad de los autores fundamentándose en la declaración de la víctima que resulta contradictoria con las pruebas aportadas, según recoge la propia sentencia, por los testigos de la defensa, consistentes en grabaciones de audio y mensajes de WhatsApp en la que la víctima relata lo ocurrido como algo en lo que quiso participar y advierte que su mayor temor es que se sepa que tales hechos se han producido.

A mi entender, el principio in dubio pro reo hubiera debido llevar a una valoración más correcta del principio de presunción de inocencia.

Sin necesidad de dudar de la veracidad del sentimiento de la víctima quien, por edad y por falta de una educación afectivo-sexual adecuada, seguramente no supo manejar la situación en la que se vio involucrada, no se puede enervar el principio de presunción de inocencia cuando las pruebas de culpabilidad no resultan contundentes, y más en los casos como este, en los que el propio tribunal incurre en una contradicción, al absolver por la relación sexual completa, entendiendo que ahí sí que existe consentimiento, y condenar por la acción inmediatamente anterior, considerando que no lo hay.

La perspectiva de género en este caso nos debe llevar a considerar que la víctima actúo con determinados sentimientos subjetivos de temor y vergüenza, por la propia consideración social de las mujeres que se muestran activas sexualmente, pero ello no debe conducir a vulnerar los derechos fundamentales de los imputados, ahora ya condenados.

La flexibilización de las garantías, la consideración de elementos subjetivos de interpretación en las valoraciones que deben ser objetivas, o al menos mixtas, conducen a la imposición de modelos penales autoritarios que son utilizados como 
excusa por la extrema derecha para derruir todo el entramado de principios asentados por los grupos feministas respetando las garantías $^{64}$.

La presión social del populismo punitivo ${ }^{65}$, alentados por los medios de comunicación el "otro brazo armado del populismo punitivo" $" 66$ de forma maniquea puede llevar, por un lado, al

64 Así está ocurriendo en España con los discursos misóginos de la extrema derecha que niega la existencia de perspectiva de género calificándola despectivamente de "ideología de género". Las actuaciones políticas de la extrema derecha en nuestro país son absolutamente negacionistas y justamente en este 25 de noviembre han impedido las, hasta ahora, declaraciones institucionales en contra de la violencia de género en diferentes ayuntamientos españoles, por ejemplo.

65 Resulta necesario traer a colación las manifestaciones que se produjeron a propósito del caso de "La Manada" frente a la Sentencia de la Audiencia Provincial de Navarra que calificó los hechos como abuso y no como violación, con tal presión que desde el ejecutivo se encomendó a la Comisión de Codificación Penal que elaborará un informe sobre la necesidad de hacer desaparecer las figuras de abuso y que todos los atentados sexuales fueran denominados agresión, en una clara manifestación de la presión popular sobre el legislativo, dando alas a las peticiones punitivistas bajo un pretendido enfoque de género. Este riesgo, materializado en una posible reforma del Código penal había sido advertido por MORALES PRATS, tomando como guía un artículo de Fernando Savater titulado "Por una justicia impopular", publicado en El País, el 27 de noviembre de 1986 (disponible en https://elpais.com/diario/1986/11/28/opinion/533516412 850215.html). Vid., MORALES PRATS, F.: La utopía garantista del Derecho penal en la nueva "Edad Media", Col.lecció Reial Academia de Doctors, Barcelona, 2015, págs. 31 a 38 .

66 Resulta especialmente interesante este pasaje de la obra de MORALES PRATS (págs. 36 y 37) citada en la nota anterior:

"Se trata de demostrar que el Estado puede hacer frente a los nuevos retos, de tranquilizar a la ciudadanía. Interesa la masa, el mensaje que llega al pueblo. Poco importa el individuo sometido a proceso; en la nueva cruzada punitiva importan los símbolos frente a la herejía criminal. Que el Derecho penal asuma una función simbólica es un postulado plausible; frente a la incertidumbre, a los tambores que anuncian la llegada de la nueva Edad Media, el Imperio en su declive se expresará en clave punitiva. La función de protección de bienes jurídicos, el principio de proporcionalidad en las respuestas punitivas, entre otros, no son valores que cotizan al alza, son un engorroso obstáculo para la eficacia punitiva. El poder judicial es asaeteado en una lógica en espiral (...) si se obstina en mantener la cultura garantis- 
sostenimiento de derechos penales autoritarios, que conviertan al hombre en un enemigo, acusando de ello al feminismo y, además, victimizando al victimario también de manera generalizada $\mathrm{y}$, todo ello, además, utilizando argumentos morales que se pueden volver en nuestra contra.

Precisamente el hecho de que una menor que se comporta de manera correcta no pueda consentir en mantener relaciones sexuales con varios jóvenes es la argumentación que utilizan tanto aquellos que entienden que hay que castigar muy duramente estos actos (ella jamás hubiera podido hacerlo) como los que defienden que la culpa es de ella por no cumplir las normas sociales de comportamiento sexual adecuado (es una tal o una cual, y si no hubiera acudido no le habría pasado) ${ }^{67}$.

Los audios de la menor a los que hace referencia la sentencia, a mi modo de ver, lo que ponen de manifiesto es el temor a las consecuencias que de sus acciones se derivan en el plano social, y al reproche que puede sufrir por los que pueden ejercer el control formal sobre su comportamiento sexual desde un punto de vista moral: sus padres y maestra ${ }^{68}$.

Ello nos obliga a recordar que la perspectiva de género como categoría analítica ha de servir para realizar una correcta

ta será criticado por los medios de comunicación, erigidos en otro brazo armado del populismo punitivo. El heroísmo no siempre es exigible y la magistratura no puede ser un colectivo inmune al proceso, porque lo que se le demanda, en muchas ocasiones no es justicia, sino la justicia popular, el justicialismo".

67 En cierto modo, la STSJ realiza un reproche ético a todos los participantes en este encuentro sexual, aunque dice que no quiere hacerlo.

68 Con ello no desvirtúo la crítica a la tendencia habitual a pensar que las mujeres que denuncian una lesión de su libertad sexual lo hacen tarde por temor a las represalias. Es cierto que esa consideración forma parte de los prejuicios que han de rechazarse a la hora de valorar la actuación de la víctima de los ataques sexuales. Sin embargo, creo que este caso es una auténtica excepción, donde la situación de la joven menor, precisamente, determina una situación subjetiva absolutamente distinta de la objetiva. Y que mal interpretada, puede traer disfunciones importantes para la propia concepción de un derecho penal garantista. 
interpretación de las normas atendiendo a la necesidad de no revictimizar, de creer a la víctima, pero no de que ello conduzca a la creación de derechos penales de excepción.

La perspectiva de género es un elemento más de la interpretación normativa, que debe ser tomada en cuenta por parte de los operadores jurídicos para eliminar la proyección de los roles y los estereotipos en la aplicación de la norma, pero no para eliminar las garantías. El hecho de no condenar, o de condenar con penas proporcionales y en atención a los criterios de presunción de inocencia, de legalidad, de proporcionalidad y de seguridad jurídica, no significa no creer a la víctima. Significa que el Derecho penal, el instrumento represor por excelencia en manos del Estado, sigue siendo un arma imperfecta que no puede (ni debe) cumplir la función promocional que algunos pretenden asignarle ${ }^{69}$.

Como tantas veces he dicho, la verdadera transformación social ha de producirse por otras vías, y no por la que destruye el Estado de derecho.

\section{Otras consideraciones. Una aproximación a la posible vul- neración del principio de culpabilidad}

Si en este punto se retoma la cuestión planteada en la STS 678/2019, de 6 de marzo, en la que, recuérdese, se discutía si el hecho de que la pareja de la mujer hubiera tomado alcohol debería llevar a calificar los hechos como lesiones comunes y no género específicas, porque no existe voluntad de someter a la esposa ${ }^{70}$, nos enfrentamos a la cuestión de si la perspectiva de

69 Un interesante trabajo de reciente publicación sobre el denominado "efecto desaliento", en relación con la proporcionalidad puede verse en COLOMER BEA, D.: "La doctrina del efecto desaliento como punto de conexión entre el Derecho penal y los derechos fundamentales", en Cuadernos Electrónicos de Filosofia del Derecho, núm. 41, 2019, págs. 97 y ss.

70 La defensa se apoya en la idea de la no aplicación automática de los tipos género específicos, sino en la necesidad de demostrar que existe una voluntad de sometimiento que es lo que caracteriza las actuaciones machistas, en 
género obliga a establecer sistemas de protección reforzados o derechos penales de excepción, que cumplan una función simbólica y promocional ${ }^{71}$.

No se trata de valorar si en los autores de los delitos de malos tratos concurre o no un error de tipo o de prohibición, por estar inmersos en un mundo patriarcal que no les deja ver con objetividad la realidad, sino de si se puede hablar de una aplicación automática de los delitos género específicos siempre que un hombre maltrata a una mujer.

En todo caso, hay que exponer estas ideas por separado.

En relación con la primera cuestión (si existe un error de tipo o un error de prohibición), creo importante traer a colación la cuestión que se planteó en una de las sesiones que tuvo lugar en el Encuentro de profesores de Mar del Plata (sept. 2019) ${ }^{72}$. La interesante cuestión versaba sobre si se podría aplicar un error en aquel hombre que, tras recibir varias negativas de la mujer a mantener relaciones, el hombre entendió que su "no" era un "sí" por su propia educación machista. La cuestión, desde un punto de vista de género es clara: no cabe aplicar el error, pues el no, siempre será no, a pesar de la influencia patriarcal de la educación en aquel hombre, que, se afirmaba, sí podía actuar bajo un error de prohibición.

Justo esta cuestión se ha planteado en la SAP de Burgos $379 / 2019$, que acabamos de comentar ${ }^{73}$.

una interpretación sistemática de los tipos de derecho penal sexuado y el art. 1 de la LO 1/2004.

71 Como es sabido, la función simbólica del Derecho penal supone la creencia de que el Derecho penal puede ofrecer una respuesta inmediata y eficaz a todos los conflictos, lo que lo convierte en una herramienta de acción política. (Vid., MORALES PRATS, F.: La utopía ..., cit., pág. 120.) En cuanto a la función promocional propia del Estado moderno, se pueden consultar, BRICOLA, F.: "Funzione promozionale, técnica premiale e Diritto penale", en Questione Criminale, n.3, 1981.

72 Justo el que origina estas páginas.

73 La STSJ de Castilla y León 12/2020, aborda esta cuestión en el fundamento de Derecho 9 negando que exista ninguno de ellos. 
El error, en este caso, se plantea sobre si la joven emitió un consentimiento válido o no, teniendo en cuenta que acude voluntariamente al domicilio donde residen los tres chicos y luego comenta con sus amigas lo que ha pasado sin indicar que fuera en contra de su voluntad, sino todo lo contrario, lo que en principio si existiera una gran diferencia de edad entre los implicados sería irrelevante ${ }^{74}$, y también si se produce un error o no sobre la edad de la víctima.

Queda descartado con base probatoria suficiente el error sobre la edad, ya que se prueba que los condenados conocían que la chica no alcanzaba los 16 años, por las relaciones que tenían ellos con familiares de la chica. Sin embargo, y lo interesante a estos efectos, es si pudo concurrir error de prohibición, considerando los autores que obraban lícitamente apoyándose su error en el convencimiento de que su actuación era lícita al ser válido el consentimiento de la menor.

A esto responde el Tribunal que las circunstancias culturales y psicológicas concurrentes en quien alega el error deben demostrar que el sujeto desconocía la ilicitud del hecho ${ }^{75}$.

En este caso afirma que para aplicar el error el sujeto debería tener la certeza (no solo la probabilidad) de que la conducta no era ilícita, lo que ocurre en el supuesto de hecho actual pues los acusados, quienes:

“(...) no podían ignorar que actuar en forma conjunta para realizar actos sexuales con la denunciante, cuya minoría de edad conocían, pudiera ser constitutivo de infracción penal,

74 La edad de consentimiento sexual penal son los 16 años (art. 183 del CP) si bien existe una cláusula de exención de responsabilidad para los casos en los que los sujetos involucrados sean cercanos en edad y madurez, con el fin de permitir a los menores de esa edad tener relaciones sexuales, pues de otro modo les quedarían absolutamente prohibidas.

75 En este sentido se puede ver la STS 336/2009, de 2 de abril, donde se aprecia un error de prohibición (vencible) en el caso de unos abusos sexuales perpetrados por un sujeto con su pareja de 12 años de edad, que desconocía la prohibición de mantener relaciones sexuales con menores por raón de su propia formación cultural (procedía de la selva ecuatoriana). 
habida cuenta de que no existió en ningún momento un consentimiento expreso y se realizó con la luz apagada, y en forma conjunta, debilitando la defensa de la víctima.

El referido error entendemos que solamente cabría en aquellos supuestos de relaciones sexuales consentidas, con una menor de edad, y atendiendo a las circunstancias personales del acusado. Así no debemos olvidar que los acusados tienen una cultura media, son españoles, y por los medios de comunicación han tenido la posibilidad de conocer, (por su gran difusión) el enjuiciamiento y condena de un grupo de personas, por un delito contra la libertad sexual.

La invocada alegada ignorancia de ilicitud, la cual no ha sido objeto de prueba, puesto que habiendo negado la realización de los actos sexuales, en ninguna de las formas reflejadas en el Código Penal, las acusaciones no han podido interrogar sobre los posibles motivos del error invocado, y si bien ha sido introducido en el trámite de conclusiones por las Defensas, al tratarse de una circunstancia que exime de la responsabilidad criminal deberá ser objeto de probanza por la parte que la alega"76.

Queda claro pues, que el hecho del error resulta difícil de aplicar, si se atiende a los criterios apuntados que no me resultan desacertados y que, desde luego, pueden incardinarse en una interpretación despojada de estereotipos de género. Es decir, si efectivamente por la situación del sujeto se pudiera demostrar su error invencible, teóricamente no habría ningún problema en aplicarlo, pero, parece difícil, y es misión del tribunal motivar porque no concurre.

Todo ello conduce, de nuevo, al primer planteamiento: ¿es posible realizar una interpretación de las normas del derecho penal sexuado que nos lleve a una aplicación automática de las mismas en todos los casos en los que un hombre agrede a una mujer?

La primera valoración ha de dirigirse a reflexionar sobre qué modelo de protección se establece en los sistemas penales

76 Fundamento Jurídico décimo de la SAP de Burgos 379/2019, de 11 de diciembre de 2019. 
frente a los atentados que sufren las mujeres ${ }^{77}$, lo que ha planteado algunas contradicciones en Sentencias dictadas por el Tribunal Supremo a propósito de la aplicación de la nueva agravante prevista en el art. $22.4^{78} \mathrm{del} \mathrm{CP}$, en las que no es posible entrar en este trabajo, por lo que lo voy a señalar simplemente.

La STS 565/2018, de 19 de noviembre establece que, en este sistema mixto es posible aplicar la agravante de discriminación por razón de género tanto a las agresiones que se producen en el ámbito de la pareja como las que acaecen fuera de él, cuando un hombre agrede a una mujer por el hecho de ser mujer, siempre que se compruebe que dicho acto lo fue por razón de discriminación de género, lo que no puede resultar más coherente ${ }^{79}$.

Sin embargo, se plantea un problema de incoherencia en relación con lo expuesto anteriormente, cuando se afirma que para los casos de violencia de género en la pareja no es necesario atender a la prueba de dicha situación de discriminación, puesto que ésta es estructural y supone la aplicación automática de los tipos género-específicos (por ejemplo, en la STS 678/2019, de 6 de marzo comentada anteriormente).

Así, la STS 99/2019, de 26 de febrero dice que, para la aplicación de la agravante prevista en el art. 22.4 (discriminación por razón de género) en el caso de que el hecho se produzca

77 Vid., LLORIA GARCÍA, P.: "La violencia sobre la mujer en el S. XXI: Sistemas de protección...”, cit., págs. 26 a 32.

78 Sobre esta circunstancia se puede ver, in extenso, OREJÓN SÁNCHEZ DE LAS HERAS, N.: La circunstancia ..., cit., passim.

79 Fundamento de derecho octavo in fine:

“(...) la agravante de género debe aplicarse en todos aquellos casos en que haya quedado acreditado que el autor ha cometido los hechos contra la víctima mujer por el mero hecho de serlo y con intención de dejar patente su sentimiento de superioridad frente a la misma; es decir, en aquellos casos en que se cometió el hecho por esa motivación, que atenta contra el principio constitucional de igualdad".

En contra de este posicionamiento, RUEDA MARTÍN, M.A.: "Cometer un delito por discriminación referente al sexo de la víctima y/o por razones de género como circunstancia agravante genérica", en RECPC, 21-04 (2019), pág. 23. 
en el ámbito de la relación de pareja, no es necesario demostrar el ánimo de dominación. Acude para justificar esta posición a toda la doctrina emitida sobre la necesidad o no de fundamentar un elemento subjetivo del injusto en los tipos que, en atención a la perspectiva de género en la fase legislativa, ya tuvieron presente el plus de antijuridicidad que supone que el hecho se produzca con ánimo de dominación machista ${ }^{80}$.

Afirma el Tribunal, atendiendo al voto particular emitido en la STS del Pleno 677/2018, que el ánimo de dominación no hay que demostrarlo en las relaciones de pareja, porque las agresiones de los varones a sus compañeras siempre son una manifestación de poder y de desigualdad. No se trata de una presunción iuris et de iure. Se trata de que basta con que el autor conozca que con su conducta coloca a la mujer en una posición de humillación y subordinación, sin que sea necesario que la busque de propósito. Esto es, lo importante no es que el sujeto sepa si tiene o no una actitud machista. Lo importante es que los hechos de agresión producen en sí mismos discriminación. Acudiendo a la doctrina sentada por el Tribunal Constitucional ${ }^{81}$ en relación con el art. 153, confirma que la asimetría hombre-mujer que ha de existir para castigar más gravemente la actuación en los delitos género específicos se refleja en las relaciones de pareja.

Recurre al fundamento de los arts. 153.1, 171.4, 172.2 y 148.8 para "predicar (que) para la aplicación de la circunstancia agravante del artículo 22.4. el mismo presupuesto objetivo de una relación específica entre el varón-autor y la mujer vícti$m a{ }^{\prime \prime 2}$, pero esto, no se puede extender más allá de las relaciones de pareja, donde afirma que "habrá de exigirse al menos una asimetría en la relación entre varón-autor y mujer-victima que sea reflejo de la discriminación que constituye el fundamento de la mayor sanción penal" ${ }^{\prime 3}$.

80 Fundamento de derecho tercero, número 2.

81 STC 59/2008, entre otras.

82 Fundamento jurídico Tercero, 3.2.

83 Ibidem 
Sin embargo, cuando no existe relación de pareja ¿qué ocurre? Pues que hay que acudir a demostrar el elemento de dominación.

Ello conduce a afirmar, de nuevo, que la perspectiva de género no puede realizarse de manera objetiva y acrítica ${ }^{84}$.

La perspectiva de género no autoriza a que se deba aceptar la existencia de una culpabilidad colectiva que derive en la aplicación automática de los delitos especiales sin demostrar la existencia de dicho elemento de dominación.

El Derecho penal de la culpabilidad normativa exige la imputación individual a un sujeto por un hecho concreto, y se le reprocha dicho hecho con los elementos y circunstancias que lo rodearon. De otro modo, el principio de culpabilidad se ve puesto en entredicho, y tiembla, de nuevo, un pilar básico del Derecho penal de los estados democráticos.

Como afirma LAURENZO COPELLO, no se puede construir la aplicación más grave de la norma por razones de discriminación a todo el colectivo porque entonces, la culpabilidad, dejaría de cumplir su función ${ }^{85}$.

\section{A modo de reflexión final}

Estas breves pinceladas solo ponen encima de la mesa un problema que merece de mayor atención y reflexión del que se puede dedicar en estas páginas. En todo caso, tras la exposi-

84 Como afirma QUINTERO OLIVARES, las perspectivas no pueden hacer que cambien las normas ni el método para analizarlas, no pueden acabar sustituyendo a la ley; lo que no significa que no se deban interpretar los hechos en atención a las circunstancias que rodean a la mujer. Simplemente, ni más ni menos, quiere decir que no se puede obviar el principio de legalidad (QUINTERO OLIVARES, G.: "La interpretación de género no es la solución", original enviado a la obra homenaje a la profesora Susana Huerta, en prensa, 2020, págs.. 3 y 4 ).

85 LAURENZO COPELLO, P.: “Hacen falta figuras género específicas para proteger mejor a las mujeres?”, en Estudios Penales y Criminológicos, vol. XXXV (2015), págs. 817 a 822. 
ción realizada, creo que resulta indudable la necesidad de incluir la perspectiva de género en las interpretaciones de las normas penales, pues resulta indiscutible que hay que tomar en consideración los derechos de las mujeres como colectivo tradicionalmente discriminado, tanto en el momento de creación de la norma como en el de su aplicación.

Aplicar la perspectiva de género como categoría analítica supone que, desde los órganos jurisdiccionales, no solo se ha de atender a las necesidades de las denunciantes desde el punto de vista procesal y asistencial, sino que los y las juezas han de despojarse de los estereotipos de género a la hora de dictar sentencias y aplicar las normas.

Esta razonable petición es la que se puede deducir de manifestaciones sociales de grupos activistas, como es el caso de "Las tesis" y su performance "El violador eres tú" que ha dado la vuelta al mundo, y también de las peticiones normativas de órganos supranacionales, que indican a los Estados que deben orientar su legislación y la interpretación de sus normas con dicha perspectiva de género, como ya he señalado.

Pero ello no supone el establecimiento automático de criterios de hiper-protección de la mujer, pues no se debe confundir el reclamo social de atención efectista orientado a resaltar las situaciones de discriminación a las que las mujeres nos hemos vistos sometidas históricamente, con la traslación acrítica de dichas demandas al ámbito técnico para conseguir su efectividad.

El activismo es y ha de ser generalista e impositivo y, por lo tanto, efectista. Por el contrario, la técnica jurídico-penal ha de buscar soluciones globales, adecuadas, válidas y eficaces. La tentación de acudir al Derecho penal como solución de todos los males no es nada nuevo en materia de violencia de género, dada la gran transcendencia mediática de la materia ${ }^{86}$. Como advierte

86 Es necesario traer el trabajo de LAURENZO COPELLO, P.: "Violencia de género y Derecho penal de excepción: entre el discurso de la resistencia y el victimismo punitivo", en CDJ, (Algunas cuestiones prácticas y teóricas de la ley orgánica 1/2004), n. 9, 2007, especialmente págs. 43 a 45. 
JERICÓ OJER, el feminismo se ha desarrollado tradicionalmente de manera contraria de las concepciones autoritarias del Derecho penal. Otra cosa es que los “( ...)partidos políticos perviertan y manipulen el discurso feminista solicitando un aumento de la represión, intentado convencer a la ciudadanía de que ellos asumen el problema social de la violencia de género de una manera más contundentemente que sus antecesores (...)"87.

Ciertamente, en el contexto actual, las presiones mediáticas sobre la justicia son muchas y muy importantes. Y por eso se hace necesario aclarar que no se puede atender a cualquier tipo de demanda, por mucha presión social que se produzca, si ello implica abandonar las tesis progresistas de mantenimiento de las garantías que son propias del Estado de derecho.

La perspectiva de género no puede servir de excusa para justificar la implementación de sistemas autoritarios que flexibilicen tales garantías al punto de que se enerve el principio de presunción de inocencia con pruebas débiles que generan dudas y llevan a olvidar el principio in dubio pro reo. Tampoco para justificar la aplicación de penas desproporcionadas al mal causado, ni por supuesto para justificar la existencia de un derecho penal de autor que olvide el principio de culpabilidad ${ }^{88}$.

$\mathrm{Si}$ obviamos dichas consideraciones las consecuencias pueden ser muy graves.

En primer lugar, se destruye la confianza en el Estado de derecho y en el derecho fundamental a la tutela judicial efectiva, algo irrenunciable desde una visión democrática y progresista como la que debe empapar a las feministas. Además, esto proporciona argumentos a los grupos de extrema derecha para victimizar al victimario y ensalzar los estigmas de la "ideología de género". Llegándose, incluso, a la propia destrucción del Estado

87 JERICÓ OLER, L.: "Perspectiva de género...”, pág. 302.

88 En este sentido, JERICÓ OLER, L.: "Perspectiva de género...”, cit., págs. 305 y 306. 
social y democrático de derecho tal y como se entiende en clave liberal ${ }^{89}$.

En segundo lugar, se coloca a las mujeres en una posición de fundamentalismo, que para nada debe identificarse con la legítima defensa de argumentos que nos permitan alcanzar la igualdad material, también en la creación y aplicación de las normas penales.

Los motivos que llevan a realizar dichas interpretaciones acríticas aupadas por las olas de lo políticamente correcto y como respuesta a peticiones populistas, acaban siendo un campo de minas que nos perjudica a todos ${ }^{90}$.

89 Como afirma MORALES PRATS, "Esta apuesta del Estado por el Derecho penal eficaz, en detrimento de las garantías, probablemente constituye una apuesta autodestructiva para el propio Estado. El abandono del modelo del Estado de Derecho y de sus límites, en favor de un Derecho penal expansivo de la nueva "Edad Media", puede llegar a constituir un factor importante de aceleración en la descomposición del propio Estado-nación. La pérdida del modelo no se produciría entonces tan solo por factores externos de la nueva época (movimientos migratorios masivos, interdependencia de la economía al margen del Estado, auge de contrapoderes localistas...), sino por factores de descomposición interna, por la propia lógica desmedida de la intervención punitiva, por el abandono de los signos de identidad del propio modelo de Estado social y democrático de Derecho."

MORALES PRATS, F.: La utopía ..., cit., pág. 38.

90 No creo necesario recordar las consecuencias que se derivan del uso indiscriminado y sin límites del poder punitivo, que olvida principios esenciales como los expuestos o al que se atribuyen funciones simbólicas, transformadoras y utilitaristas. En este sentido, me parecen muy ilustrativas las palabras de MORALES PRATS cuando, al hilo de la evolución del Derecho penal a partir de los años 90 del siglo XX afirma que :

"Se dibujaba así un escenario en el que el Derecho Penal podía asumir funciones de orientación cultural, vinculadas a la amenaza penal, o bien de promoción de incentivación de valores ético-sociales a través de su afirmación simbólica. Esta línea evolutiva se ha enraizado férreamente en los últimos años y ha quedado plasmada en las últimas reformas del Código penal de España".

MORALES PRATS, F.: La utopía ..., cit., pág. 127. Las consecuencias son expuestas con gran claridad en la misma obra, en pág. 130. 


\section{BIBLIOGRAFIA}

AAVV.: Las huellas de "La Manada", Monográfico de la Revista El Cronista del Estado Social y Democrático de Derecho, IUSTEL, 2018, núm. 77.

ACALE SÁNCHEZ, M.: "El género como factor condicionante de la victimización y de la criminalidad femenina", en Papers, 102/2, 2017. https://doi.org/10.5565/rev/papers. 2337

ALONSO DE ESCAMILLA, A.: "La reforma de los delitos contra la intimidad" en Morales Prats, F., Tamarit Suma1la, J.M. y García Albero, R. (Coord.): Represión penal y Estado de Derecho. Homenaje al Profesor Gonzalo Quintero Olivares, Aranzadi, 2019.

BELTRÁN MONTOLIU, A.: "Víctima de violencia de género y la dispensa del art. 416 LeCrim: evolución jurisprudencial", en Revista de Derecho penal y Criminología, $3^{a}$ Época, núm. 19 (enero de 2018). https://doi.org/10.5944/ rdpc.19.2018.24408

BODELÓN, E.: "La violencia contra las mujeres y derecho no androcéntrico: perdidas en la traducción jurídica del feminismo", en Laurenzo Copello, P., Maqueda Abreu, M.L. y Rubio Castro, A.M. (coords.): Género, violencia $y$ derecho, Tirant lo Blanch, 2008.

BODELÓN, E.: "Derecho y justicia no androcéntricos", en Quaderns de psicología, num. 2, 2010.

BODELÓN, E.: "Violencia Institucional y violencia de género", en Análes de la Cátedra Francisco Suarez, 48, 2014.

BRICOLA, F.: "Funzione promozionale, técnica premiale e Diritto penale", en Questione Criminale, n.3, 1981.

COLOMER BEA, D.: "La doctrina del efecto desaliento como punto de conexión entre el Derecho penal y los derechos fundamentales", en Cuadernos Electrónicos de Filosofía del Derecho, núm. 41, 2019.

CRUZ MÁRQUEZ, B.: “Configuración legal y desarrollo normativo de la práctica penitenciaria frente a la 
delincuencia de género", en Juanatey Dorado, C. y Sánchez Moraleda, N. (Dir.): Derechos del condenado y necesidad de pena, Aranzadi, 2019.

CUGAT MAURI, M.: "La ambivalencia de la protección de la libertad sexual. Jurisprudencia del Tribunal Supremo sobre el delito de violación", en Jueces para la Democracia, núm. 20, 1993.

DABOVE, M.I. Y ARRUBIA, E.: “¿Demasiado vieja para el sexo?", en Derecho y Ciencias Sociales; núm. 19, disponible en http://sedici.unlp.edu.ar/handle/10915/70779

FACIO, A.: "Hacia otra teoría crítica del Derecho", en HERRERA, G.: Las fisuras del patriarcado. Reflexiones sobre Feminismo y Derecho. Ponencias en el Programa de Género de FLACSO organizadas por el seminario "Género y Derecho: reflexiones desde la teoría y la práctica”, Ecuador., 2000, págs. 15 a 44, passim, disponible en http://www. flacso.org.ec/docs/safisfacio.pdf)

FACIO, A.: Cuando el género suena, cambios trae: (Una metodología para el análisis de género del fenómeno legal), Ilanud, 1992.

GARCÍA ARÁN, M. Y BOTELLA CORRAL, J. (Dirs.): Malas noticias. Medios de comunicación, política criminal y garantías penales en España, Tirant lo Blanch, 2009.

GARCÍA PRINCE, E.: Políticas de Igualdad, Equidad y Gender Mainstreaming. ¿De qué estamos hablando?: Marco Conceptual. Edición revisada y actualizada, disponible en http://www.americalatinagenera.org/es/documentos/ doc_732_Politicasdeigualdad23junio08.pdf

GIMBERNAT ORDEIG, E.: "Imputación objetiva y conducta de la víctima", disponible en https://www.boe.es/publicaciones/anuarios_derecho/abrir_pdf.php?id=ANUP-2005-30073300806

GÜNTHER, J./ CANCIO MELIÁ, M.: Derecho penal del enemigo, Civitas, 2006.

JERICÓ OLER, L.: "Perspectiva de género, violencia sexual y derecho penal", en Monge Fernández, A. (Dir.): Mujer 
$y$ derecho penal. ¿Necesidad de una reforma desde una perspectiva de género?, Bosch, 2019. https://doi. org/10.2307/j.ctvq2w28r.13

LARRAURI PIJOAN, E.: "La mujer ante el Derecho penal", $R D P C$, n. 2, 1992.

LARRAURI PIJOAN, E.: Género y Derecho penal, disponible en http://www.cienciaspenales.net/files/2016/09/5genero yderechopenal11.elenalarrauri.pdf

LAURENZO COPELLO, P.: “¿Hacen falta figuras género específicas para proteger mejor a las mujeres?”, en Estudios Penales y Criminológicos, vol. XXXV (2015).

LAURENZO COPELLO, P.: "Violencia de género y Derecho penal de excepción: entre el discurso de la resistencia y el victimismo punitivo", en $C D J$, (Algunas cuestiones prácticas y teóricas de la ley orgánica 1/2004), n. 9, 2007.

LLORIA GARCÍA, P.: "La expansión del Derecho penal en su aplicación judicial: la violencia de género como ejemplo paradigmático", en García Rivas, N. y Riquert, M.A.(Dirs.): Garantías penales en Argentina, España y sus sistemas de inserción regional, Ediar, Buenos Aires, 2011.

LLORIA GARCÍA, P.: "El control tecnológico como violencia de género" disponible en http://agendapublica.elpais. com/el-control-tecnologico-como-violencia-de-genero/

LLORIA GARCÍA, P.: "La regulación penal en materia de violencia familiar y de género tras la reforma de 2015. Especial referencia al ámbito tecnológico", en $R G D P$, núm. 31, 2019.

LLORIA GARCÍA, P.: "La violencia sobre la mujer en el S. XXI: Sistemas de protección e influencia de las tecnologías de la información y la comunicación en su diseño", en Lloria García, P. (Dir.) y Cruz Ángeles, J.: (Coord.): La violencia sobre la mujer en el S. XXI: Género, Derecho y TIC, Aranzadi, 2019.

MAQUEDA ABREU, M.L.: Razones y sin razones para una criminología feminista, Dikynson, 2014. 
MAQUEDA ABREU, M.L.: "La violencia de género. Entre el concepto jurídico y la realidad social", RECPC, 2005.

MORALES PRATS, F.: La utopía garantista del Derecho penal en la nueva "Edad Media", Col.lecció Reial Academia de Doctors, Barcelona, 2015.

OLSEN, F.: "El sexo del derecho", en KAIRYS, D. (ed.). The Politics of Law, Nueva York: Pantheon. Traducción de Mariela Santoro y Christian Courtis, disponible en http:// www.derechoshumanos.unlp.edu.ar/assets/files/documentos/el-sexo-del-derecho.pdf

OREJÓN SÁNCHEZ DE LAS HERAS, N.: "Derecho penal y cultura de la violación con ocasión del caso de 'La Manada"”, en Lloria García, P. (Dir.). y Cruz Ángeles, J. (Coord.): La violencia sobre la mujer en el S. XXI: Género, Derecho y TIC, Aranzadi, 2019.

OREJÓN SÁNCHEZ DE LAS HERAS, N.: La circunstancia agravante genérica de discriminación por razones de género, Iustel, 2019.

PÉREZ RIVAS, N.: Los derechos de la víctima en el sistema penal español, Tirant lo Blanch, 2017.

POYATOS, G.: "Prólogo", en Gisbert S.: Balanza de género, Lo que no existe, 2018.

QUINTERO OLIVARES, G.: "La tutela penal: entre la dualidad de bienes jurídicos o la perspectiva de género en la violencia contra la mujer", Estudios penales y criminológicos, vol. XXIX, 2009.

QUINTERO OLIVARES, G.: "La interpretación de género no es la solución", original enviado a la obra homenaje a la profesora Susana Huerta, en prensa, 2020.

RAMÍREZ ORTIZ, J.L.: "El testimonio único de la víctima en el proceso penal desde la perspectiva de género", en Quaestio Facti. Revista internacional sobre razonamiento probatorio, Vol. 1, 2019, disponible en https://revistes.udg. edu/quaestio-facti/article/view/22288/26046. https://doi. org/10.33115/udg_bib/qf.i0.22288 
RUEDA MARTÍN, M.A.: “Cometer un delito por discriminación referente al sexo de la víctima y/o por razones de género como circunstancia agravante genérica", en $R E C P C, 21$ 04 (2019).

RUIZ RICO, J.J.: El sexo de sus Señorias, 4a ed., Comares, 2011.

SILVA SÁNCHEZ, J.M.: La expansión del Derecho penal: aspectos de la política criminal en las sociedades postindustriales, Edisofer, 2011.

VILLACAMPA ESTIARTE, C.: Política criminal española en materia de violencia de género. Valoración crítica, Tirant lo Blanch, 2018. 